Original Research Paper

\title{
Theory Practice Gaps in Nursing Education: A Qualitative Perspective
}

\author{
Ahmad Saifan, Mohannad Eid AbuRuz and Rami Masa'deh \\ College of Nursing, Applied Science Private University, Amman, Jordan
}

\author{
Article history \\ Received: 30-01-2015 \\ Revised: 11-03-2015 \\ Accepted: 18-03-2015 \\ Corresponding Author: \\ Ahmad Saifan \\ College of Nursing, Applied \\ Science Private University, \\ Amman, Jordan \\ Email: saifan50@yahoo.com
}

\begin{abstract}
The last three decades have focused on moving the nursing education from the hospitals toward the universities. The theoretical part has started to gain more popularity in nursing education. The literature shows that there is a clear gap between what is taught in the classroom and what the student nurses experience in the clinical area. This study aimed to identify the reasons for this gap and present suggestions to overcome it. An exploratory qualitative approach was adopted. Individual face-to-face semi-structured interviews with thirty students were done. The findings shed light on one main theme "the reasons for theory-practice gap". Many of the students explained that the lack of qualifications of the clinical instructors formed a key stone in increasing the gap between theory and practice. Lack of communication between Theory and Practice teachers was viewed as another reason for this gap. The students showed the complexity of the clinical learning environment in comparison with the theory controlled environment. Poor communication between clinical instructors and lack of support in the clinical training was viewed crucial and was expected to increase the feelings of frustration and dissatisfaction among nursing students. In conclusion, qualitative design used in this study provided deep and rich data about the theory-practice gaps in nursing education in Jordan. The results of this study could be useful for the undergraduate students, the nursing schools, the nursing teachers and the stakeholders in Jordan.
\end{abstract}

Keywords: Theory-Practice Gap, Nursing, Education

\section{Introduction}

The last three decades focused on moving nursing education from hospitals to the universities. There is point of view shows that nursing is a practice discipline and the students' clinical training is considered to be the core of nursing education (Jonsén et al., 2013; Parker and Carlisle, 1996). It was suggested that theory as being complementary to practice and they expect more focus on teaching in the clinical setting (Landers, 2000). This view was originated from the ability of clinical education to provide students with real life events that enable them to develop, apply and evaluate their own understanding of concepts being studied (Ranse and Grealish, 2007). However, other authors did not ignore the importance of theory in nursing education (Stockhausen, 2005). They believed that theory information provides students with the opportunity to build a range of powerful exemples that gained from experience.

The theoretical part is started to gain more popularity in nursing education. Several programs and subspecialists are newly developed and this reduced the concentration on clinical education. Nursing teachers also started to focus on research and theory more than the clinical skills. Nolan (1998) indicated that existing curriculum content and clinical experiences were failing to meet learners' needs. Jeffreys (2007) explained that this failure is resulted from making the clinical education secondary to the priorities of the services.

The literature showed that there is a clear gap between what is taught in the classroom and what the student nurses experience in the clinical area (Brasell-Brian and Vallance, 2002; Landers, 2000; McKenna and Wellard, 
2004). This gap was viewed as a normal phenomenon by some authors. For example, (Steele, 1991) explained that what is taught in the classroom can never truly resemble the real event and that a full comprehension of nursing principles does not ensure their application to practice. In the same vein, (McCaugherty, 1991) pointed out that textbooks cannot possibly give the full picture of a patient's clinical status. This suggests that the theorypractice gap is difficult to be avoided. However, there is a limit for this gap should not be exceeded. The above discussion shows the difficulty of avoiding theorypractice gap in nursing education. The literature review highlighted several reasons for presence of this gap. The nursing theorists use abstract expressions to define rules and procedures in the clinical domain (Hislop et al., 1996). These abstractions are usually not clear and could be interpreted in different ways. Upton (1999) stated that nursing theorists assign different meanings to the same term. This produces confusion between nurses who might find a difference in definition of the same term between two or more authors (Landers, 2000).

Theory-practice gap is increased in post graduate education in nursing (Fairbrother and Ford, 1998). Presence of tertiary education in nursing and the concentration of nursing schools on research and academia reduced the focus on practice training (McKenna and Wellard, 2004). Hickey (1996) surveyed student nurses' reflections on their educational experiences. More than five hundred students in their final year were surveyed. With a response rate of $80 \%$, Hickey reported that more than $50 \%$ of the students felt that there was lack of emphasis given to practice education in the classroom. However, the students did not specify what they exactly mean by practice education.

It was argued that the clinical environment is complicated and continuously changed (Landers, 2000; Nabolsi et al., 2012). Therefore, it could be suggested that even the very effective theoretical input in the classroom could never cater for the complexities of the clinical situation (McCaugherty, 1991). Consistently, it was explained that not all students will have the same opportunity and experience in the clinical field (White and Ewan, 1997). This may result in some students being better equipped than others to integrate to practice (Landers, 2000). For example, there are some departments in the clinical area have workload more than other departments. This would reduce the encouragement of students to learn (Landers, 2000). There are other departments where routine and ritual prevails do not encourage students' initiative and creativity.

The role of nursing teachers to link theory to practice was viewed as a crucial in overcoming the theorypractice gap. Hartigan et al. (2009) stated that nursing teachers are not involved in direct patient care. In contrast, they have only theoretical perspective about clinical situations. This may hinder their ability to maintain clinical credibility and limit their clinical interaction with students in the clinical setting (Hartigan et al., 2009). Hewison and Wildman (1996) indicated that the teachers' ability to deliver the theoretical input to their students is important to close this gap. They explained that that the theory-practice gap will be increased if the theory learned in the classroom is not clear for the students.

Previous literature shows that there is an apparent theory-practice gap between nursing education and nursing practice (Hartigan et al., 2009). This phenomenon was described as a "gap between 'what is taught' and 'what is practiced' in nursing", where the theory concentrate the ideal for patient care, whilst the clinical education focuses on the reality of nursing work (Budden, 1994). This study aimed to identify the gaps between theory and practice in nursing education within the Jordanian context.

\section{Materials and Methods}

Qualitative researchers believe that reality is understood through people sharing experience and interaction with others (Cohen et al., 2000). This study aimed to explore how students behave in the clinical setting according to what they learn in theory and what are the factors that influence the theory-practice gap. Therefore, the focus was on understanding the phenomenon under investigation through interaction with nursing students who are expected to deepen our understanding of this phenomenon (Bryman, 2012). Another reason for adopting qualitative design was because we were the first private university in Jordan that studied the experience of students in the clinical setting and the factors that influence the theory practice gap. Rich and deep information was expected to be produced from using this approach. This was expected to be achieved through inviting the students to describe their experience freely and without inhibition or constraint.

\section{Data Collection}

Individual, semi-structured, in-depth interview was selected as the method of data collection for this research. This allows high validity and gives the interviewees the freedom to talk in depth about their experiences and emotions (Polit and Beck, 2010). In the current study, an interview schedule was developed depending on the literature and our experience the participants were firstly asked about the driving forces behind selecting the nursing specialist. The students then were asked about their experiences of moving between the theory education in the school and the practical training in the hospitals. Questions about the possible reasons for theory-practice gaps in nursing education were also asked. Finally, the 
students were asked if they have any more information or notes about this phenomenon.

\section{Sample}

Purposive sampling strategy was used in this study. Participants were students with the major of nursing. Thirty students were recruited in the current study (Table 1). The recruiting for students continued until the point of saturation. The sample included of both males and females. The female students were more than the male. This is resulted from the fact that our department consists of only about 140 students which are mostly females. The population targeted was students attending the Applied Science University who took clinical courses. The selected students had attended at least two clinical courses because they would have a full understanding of the topic of this study and have had enough clinical practice to compare to what is taken in theory. The second, third and fourth year students were selected because this is the group that is more likely to have taken at least two clinical courses. We excluded bridging students because most of these students have had working experience in the hospitals and it would be hard to relate to the theory-practice gap.

\section{Recruitment of Participants}

Three volunteered nursing students helped in the process of data collection. These students received training about conducting interviews. Selecting students to do the interviews was done to avoid bias in data collection. The students were expected to find it difficult to critique the teachers in the school or the educational process. To avoid any of these incidents, it was thought that doing interviews by students from the same school will ease the process of data collection. Deeper and richer data about the phenomenon under investigation was also expected to be produced. Two plans were followed in the recruitment process. The first one was sending an invitation letter. Invitation letters for students were prepared and distributed to all eligible students in the school. Posters about the study were presented on the students' board. These letters and posters contained brief information about the researchers, information about the research topic and the goal of this study. Phone numbers and email addresses of the researcher were provided. Those who want to participate can contact the researcher and arrange for a time and a date to be interviewed. The second plan was face-to-face recruitment. This includes talking to the students directly about the research and what is the benefit of it. Information sheet was given to all most of the students in the school. Finally, all students who met the inclusion criteria and accepted to take part in the current study were invited to be interviewed. Each participant was given a consent form to be signed at the beginning of the interview.
Table 1. The demographical information for the study sample

\begin{tabular}{|c|c|c|}
\hline Student number & Gender & Year \\
\hline Student 1 & Female & 4 th year student \\
\hline Student 2 & Male & 3rd year student \\
\hline Student 3 & Female & 3rd year student \\
\hline Student 4 & Male & 2nd year student \\
\hline Student 5 & Female & 4th year student \\
\hline Student 6 & Male & 4th year student \\
\hline Student 7 & Female & 4th year student \\
\hline Student 8 & Female & 4th year student \\
\hline Student 9 & Female & 3rd year student \\
\hline Student 10 & Female & 4th year student \\
\hline Student 11 & Female & 4th year student \\
\hline Student 12 & Male & 4th year student \\
\hline Student 13 & Female & 3rd year student \\
\hline Student 14 & Male & 2nd year student \\
\hline Student 15 & Female & 4th year student \\
\hline Student 16 & Female & 3rd year student \\
\hline Student 17 & Female & 2nd year student \\
\hline Student 18 & Female & 3 rd year student \\
\hline Student 19 & Male & 4 th year student \\
\hline Student 20 & Male & 2nd year student \\
\hline Student 21 & Female & 3 rd year student \\
\hline Student 22 & Female & 3 rd year student \\
\hline Student 23 & Female & 4 th year student \\
\hline Student 24 & Male & 4th year student \\
\hline Student 25 & Male & 4th year student \\
\hline Student 26 & Female & 2nd year student \\
\hline Student 27 & Female & 3rd year student \\
\hline Student 28 & Female & 3 rd year student \\
\hline Student 29 & Female & 4th year student \\
\hline Student 30 & Male & 2nd year student \\
\hline
\end{tabular}

\section{Ethical Issues}

Ethical approval was obtained from the college of nursing at the Applied Science Private University. Autonomy, confidentiality and voluntary participation of the participant were granted). Each student in the present study had the right to decide voluntarily whether to participate in a study, without risking any penalty or prejudicial treatment. All participants were received enough information about the study purposes before starting the interviews. Each participant was asked to sign a consent form and was told that they could change their minds during the research and can withdraw and withhold information at anytime. All participants were informed that their responses would be treated confidentially and anonymously. Additionally, all the students were interviewed in one of the school empty classrooms during hours when class was not in session.

\section{Data Analysis}

Braun and Clarke (2006) technique of thematic analysis was utilized to analyse our data. Interviews were transcribed verbatim by one of the researchers. The initial data analysis and coding were carried out 
by one of the researchers. Two of the researchers reviewed the transcriptions and they produced their own codes, separately. Both interpretation of the data analysis was largely consistent. The first phase of data analysis was familiarisation with the data. This was achieved by active listening to the interviews and selftranscription by one of the researchers. The second step includes generating initial codes. All transcripts were entered into the NVivo software. All interviews were carefully read and examined line-by-line. We always asked ourselves "what did this person want me to understand by saying this?" The third phase includes searching for themes. The fourth phase includes reviewing the themes. Once all the data had been entered, the codes were refined. The fifth phase includes defining and naming the themes. At this step, five themes were assigned. The final phase of data analysis includes producing the report. This phase formed the starting point of writing our results section.

\section{Results}

Nursing education is among the best in the MiddleEast. Jordan exports nurses to all the surrounding countries. To maintain this level of nursing education, it seems important to consider all issues that may negatively influence the quality of this education within the Jordanian nursing schools. The issue of theorypractice gaps in nursing education was rarely studied in Jordan. Using a qualitative design, this study provides rich and deep information about the experiences of nursing students during their study. The participants explained that there is a clear gap between what they taught in the theory part and what they found in the clinical area. The students had raised several reasons for this gap. These reasons were collected together and built the major theme in the current study "the reasons for theory-practice gap in nursing education". The Table 2 shows how these subcategories had built the major theme.

\section{Reasons for Theory-Practice Gap \\ Clinical Instructors' Qualifications}

The qualifications of the clinical instructors were ranked the highest reason for theory-practice gap in nursing education. Around half of the participants said that their instructors were qualified and that they had enough experience to teach them what they needed to be learned. However, the other half said that not all of their clinical instructors were qualified enough:

When I took Adult 1 module, I did not learn anything. I felt that the semester was not

\begin{abstract}
beneficial. The clinical instructors did not teach us anything, like not even medications or basic skills. Literally nothing, even if someone came with a certain case I did not know what was the first thing I should do, nobody helped us or taught us how (Student 3).
\end{abstract}

It should be clear that the clinical instructors are certified and licensed to practice the nursing profession in Jordan. This is a condition to recruit these instructors in the nursing schools in the Jordanian universities. It is generally known that each instructor should have at least a bachelor degree in nursing to train the students in the clinical area. Moreover, many of them have higher qualifications such master degrees and $\mathrm{PhD}$ in one of the nursing branches. So, what is the problem? When this point discussed deeply and the students were asked about the meaning of "not qualified" from their perspectives, they answered that "not qualified" means that the instructors are not able to give attention to the students. They also missed the support that they expected to get from their instructors when they needed it. It was indicated by a considerable group of students that some of the instructors do not have good communication skills. Lack of knowledge and skills was also indicated by some students. Some instructors concentrate on the marks rather than the students understanding of the information:

\section{The instructor was available for the students and would make case discussions but it seemed only for the mark and grade purposes. They wouldn't explain procedures or apply what we take in the theory (Student 14).}

The participants talked frankly about an interesting point. They stated that some of the clinical instructors may have good knowledge and certificates but they do not have clinical experience. This made it difficult for these instructors to link the theory with practice. Instead of doing this, they focused more on the theory part even in the practice area. According to some of the participants, the clinical instructors may do this to hide their inability of implementing the theoretical information in the practice area:

I just think they do not know what they are doing, it is not their actual major and so they do not know how to give us the actual information so they stick behind the criteria and impose it on us. If it was their major we would learn more, gain experience and the course would be more enjoyable (Student 5). 
Table 2. Overview of the categories resulted from the interviews

The subthemes
Clinical instructors' qualifications
Lack of communication between theory and practice teacher
Teachers and instructors do not consider differences between students
Material given in theory and its sequences
Poor communication
Number of students and time management

\section{Lack of Communication between Theory and Practice Teacher}

The theory and practice work together to produce high quality nurses. This could be achieved by cooperation and communication between the theory and the practice teachers. The students said if communication occurs between the theory teachers and the practice instructors, they will know what they took in the theory and what they applied in the practice. Therefore, they will make a connection between the theory and the practice. Most of the students indicated that there are good channels of communication between the theory teachers and the clinical instructors. They said that their clinical instructors, in many occasions, linked the practice with what was taken in the theory classes. This was viewed as a positive issue in decreasing the gap between the theory and the practice nursing education:

\begin{abstract}
All the clinical instructors who go with us to our clinical courses would explain something and then they will say you guys took this in theory. So obviously our teachers and instructors communicate. They always know exactly what we took (Student 2).
\end{abstract}

However, the above scenario was different from the point views of many of the interviewees. The students disagreed and said that their biggest problem was that they felt that their teachers did not communicate to facilitate easier learning for them. They wished to strengthen the bridge between the theory teachers and their clinical instructors. Student 6, for example, commented on this point:

They give us different information, different sequence and each of them set a different goal and need. Sometimes the teacher asks for something and the instructor asks for something else. They have different expectations. Sometimes one will ask for a little less than the other and one will ask for more. I think if they were the same person it would be easier (Student 6).

\section{Teachers and Instructors do not Consider Differences between Students}

Many of the students said that one of the problems they faced with their theory teachers and clinical instructors was that they did not consider the differences between them. They explained that each one of them is a unique individual who learns in certain ways and that some teachers had only one teaching method which made it difficult for them to understand the information. Their major complaint was that the teacher always made group discussions and did not focus on each student alone. Even though most of the students received the information given and processed it, they did not:

\section{I think that the teacher should give each student a specific day in which the teacher makes sure that the student is doing his/her role as a student to the fullest and helps him/her answer his/her questions (Student 14).}

On the other side, there are other students recommended group discussions as an effective teaching method. They recommended case-study teaching. This means to see an actual case in the hospital and then discuss this case with all students and give them the chance to participate in the discussion. This method was viewed convenient for many of the students in this study. However, a few participants explained that there are differences between the students' needs in the theory education and the practice training. The methods that are expected to be convenient in the theory education may not be suitable for the practical education. Teachers deal with large numbers in the theory part. The participants showed that some of the clinical instructors used the same methods of education that usually used in the theoretical education:

To be honest, the instructors in the clinical area deal with us as we are in lectures. I think that the clinical training is different and sometimes we have special needs. Some of the instructors do not consider the differences between the theory and the practice parts of nursing education (Student 28). 
Remarkably, all the students explained the importance of using different methods of teaching. Some of them favored the individual teaching or the small groups teaching, while others preferred the large group discussion. Clinical instructors should evaluate their students and they should try to reach them. Recognizing the learners' needs would be expected to decrease the gaps between the theory part and the practice part.

\section{Materials Given in Theory and its Sequences}

Theory is about building a knowledge base and learning about disease processes, signs and symptoms, interventions, etc. On the other side, clinical practice focuses on skills more than knowledge. Students have to be quick and skillful while working in the clinical area. Some students had a hard time connecting between theory and practice due to the reality that they were different to a considerable extent:

Well, theory is a lot different than reality. I feel that in theory we just learn all this stuff and all this information and it is just a bunch of stuff and we sit there and the teacher just talks and talks and goes on forever and yeah you have an idea about the disease but really it does not help you in the clinical area. In the clinical area, I just feel like we do not actually apply all that we learn (Student 3).

Some of the students said that they felt that the clinical area was not about learning rather grading and marks. The clinical instructor would have a grade setting criteria and if they followed these criteria they will get the highest grade even if they did not actually understand what they were doing. They did not have any space for critical thinking; you just memorized steps and worked by them. For example, student 3 commented on this and said:

I felt like it was about grades, we would pretend like we were working when the clinical instructors came and we would write some stuff on the paper ... it was all about our marks (Student 3).

Because of their academic backgrounds, the teachers focus more on the theoretical part even in the clinical area. According to several students, this would limited the benefits from clinical training and made it boring. In Jordan, clinical experience is not a condition to be nursing teacher. Many of the nursing teachers in Jordan never worked in hospitals. They continued their study and became nursing teachers. They depend on their clinical training while they were students in the universities. This may interpret the views of the above students of not considering the clinical skills and the focus more on grading.

It was not just the marks that were the problem. It was the nature of the material given in the theory and the difference between it and between the clinical areas. They feel like the knowledge learned is of no use in the clinical area. Therefore, they did not understand why it was so important to learn it all. The next two quotes are examples:

\begin{abstract}
In theory we would take more about the actual scientific side of nursing and about body systems and diseases, but in the clinical area we hardly dealt with that kind of things. The clinical setting is complex and I think that the theory does not consider all the factors that are presented in the clinical area. For most of the practical education, it was basically based on memorizing everything the clinical instructor wanted from us. It was more about getting points and getting marks than actually learning and actually doing something beneficial for the hospital and for the patients there (Student 5).
\end{abstract}

The theory should consider the complexity of the clinical area. Changing the way of education in the theoretical part of nursing education would decrease the gap between theory and practice. This could be done by different methods. For example, the nursing teachers may present real case studies from the local clinical area and discuss it with the students in the class (Student 22).

The student in the above statement explained that the focus of theoretical education is on pure science. However, nursing is classified under the social science. Dealing with patients and their relatives could not be taught from a pure scientific background. Giving real examples and case studies would help the students to deal with these situations. This supports the above discussion that the nursing teachers should have clinical experience as a condition to teach.

\section{Poor Communication}

Communication was viewed as key factor to support the students to adapt with the clinical area. It was explained that the good communication between the clinical instructors and the students facilitated the training process in the clinical area. Surprisingly, more than half of the interviewees complained that they lacked support in the clinical area and they were treated improperly by their instructors. This caused a bigger gap for most of them. The instructor expected the students to 
know how to behave like a nurse from day one. They asked questions that made them feel stressed.

The attitudes of the instructors toward the students who do not know the answers for the instructors' questions were viewed inappropriate. The instructors may use some verbal or nonverbal signs mean that it is a stigma for the students not to be prepared or when they do not know the answers for their questions. They claimed that the instructors lacked communication skills and they would make them feel bad about themselves and that they lacked of knowledge. Another thing was the judgmental attitude of some clinical instructors. Some of them would have an idea about a student and even if the students tried to work on themselves the instructor wouldn't change their mind about them. This made some students feel inferior and disapprove of their teachers' communication skills:

\section{Some of them have poor communication skills. Some of them do not belong in that clinical setting they should be teaching something else (Student 5).}

The above view was rejected by several students. They showed that they had all the support from their instructors:

\begin{abstract}
Some instructors support you and make you feel that you are a student and you are still learning and now you are not a nurse. They make you feel it is not a shame to be wrong or to make a mistake. This enhances me to ask more with no shame of not knowing and I learned from them things not only related to nursing skills. They taught me to see patients as a human and communicate with them positively (Student 8).
\end{abstract}

\section{Number of Students and Time Management}

The instructor-students ratio was viewed as an important factor in producing effective education. The ratio is wider in the theory classes than the ratio in the clinical setting. Dealing with smaller number of students was expected to reduce the gaps in nursing education. One of the students saw that the large number of students in the class affected his ability of learning and understanding. This student showed that dealing with large number of students will influence on the time specified for each student. This may restrict the ability of the nursing teacher to make a group discussion and to practice what was taught in the theory:

In the pediatric course, there were no problems present. But in the maternity course, the teacher did not have enough time to explain and apply our role in the clinical area or to do procedures (Student 11).

Despite the importance of the above statement, the instructor-students ratio was viewed problematic. Most of the students explained that this ratio is acceptable. Student 26 saw that the number of the students did not affect her learning. She explained that there are many universities have a huge number of nursing students in one class. She indicated that her school has a small number of students in each class and this is not a problem to cause a gap:

\section{If I told you it's the number of student I will be a liar, because 15 students is not a large number according to the other universities. So I don't know what the reason is (Student 26).}

Downplaying the role of students' numbers in the classes by many of the students does not mean that the number is not an important issue in the theorypractice gap in nursing education. The influence of the number of students on the quality of nursing education was discussed in literature (Nabolsi et al., 2012; Newton et al., 2009). Raising this problem by some students may reflect that the problem is existed in some practical courses, but not all of them. It could be argued that the smaller the number of the student in the class will decrease the gap between what was taught in the theory and what was viewed by the students in the clinical setting. This will give more space for the teachers to deal individually and sometimes separately with each student alone.

\section{Discussion}

This study is one of a few studies adopted qualitative design to explore the gaps between the theoretical and the practice parts in nursing education in Jordan. Most of the interviewees explained that there is a clear gap between the theory and the practice in nursing education. They indicated several reasons for presence of this phenomenon. The findings of the current study is in agreement with the findings of previous Jordanian study (Nabolsi et al., 2012), who found that nursing students do not receive good support in the clinical training. The findings of this study raised several reasons for the theory-practice gaps in nursing education. One of the most important reasons included the instructors' qualifications. In this vein, Nahas et al. (1999) examined the Jordanian undergraduate nursing students' perceptions of effective clinical teachers. The instructors qualifications were viewed crucial to improve the nursing education level. Some students in the current study stated that their instructors in the clinical settings 
were not qualified enough. However, all the instructors were certified and many of them had high degrees in different nursing branches. Therefore, the problem seems not in the qualifications of the instructors. It might be resulted from absence of clinical experience for some of these instructors. In Jordanian nursing schools, to be a nursing teacher is not a condition to have clinical experience. This may explain what was reported by some of the interviewees who explained that the instructors focus on grades and ignore the practical skills. This may also explain the reasons for presenting the lectures in the theory in purely scientific manner and do not give real examples or case studies.

Nabolsi et al. (2012) showed the importance of preparing nursing teachers and clinical instructors to improve nursing education. They explained the need for providing the students with opportunities to demonstrate competences. In nursing education, teachers and instructors need specific skills and qualifications to be able to deal with nursing students. As previously indicated, the Jordanian nursing teachers are certified and licensed to practice their job. However, there is no preparation for these instructors to work as teachers. They finish their education (bachelor, master and doctoral education) and directly start to teach in nursing schools. In most scenarios, they learn how to teach by trial and error. This may explain the views of many nursing students in the current study who thought that nursing teachers and instructors were not qualified to teach or that they did not consider different methods of teaching.

Many students stressed on the importance of building bridges between the nursing teachers in the school and the clinical instructors. This is in agreement with several studies in this field (Chapple, 2004; Gallagher, 2003; Nabolsi et al., 2012). All these studies stressed on the importance of communication and coordination between the nursing educators in the nursing schools and the clinical instructors and the clinical settings. In the current study, all the students agreed that there should be a rhythmic relationship between the theory materials and the practical training. The theory should start the journey and the practice will continue it. Both of them are working together to produce knowledgeable and skillful nurses.

Linking the theoretical information with practice was one of the challenges that faced the students in the current study. Many of them explained that they do not know exactly how to use this information in their clinical training. More interestingly, some of the students thought that theoretical education was in one world and the practice was in different world. The challenge of transferring theory to practice in nursing education is not surprising. This challenge was clearly indicated in the literature (Nabolsi et al., 2012). However, the theory teachers and the clinical instructors should prepare the students to the fact that there are differences between the practice environment's complex social context and the more controlled theory environment (Chan, 2004).

The importance of supporting nursing students in the clinical area was discussed in several studies (Brown et al., 2008; Clare et al., 2002). It was explained that clinical instructors should have special communication skills and they should receive special training and preparation to deal with the students in the clinical area (Newton et al., 2009). Failing to support nursing students in the clinical area may produce feelings of dissatisfaction and frustration for these students (Nabolsi et al., 2012). In the current study, it was indicated by some of the students that they did not receive good support during their clinical training. Some of them indicated their upset of the way of communication from some of the clinical instructors. Therefore, the findings of this study suggest the need for preparing the clinical instructors to increase their competence of doing their job. This could be achieved by passing them through special communication skills courses and by increasing their clinical competences.

\section{Conclusion}

The current research aimed to identify the gap between theory and practice in nursing education within the Jordanian context. A qualitative approach was adopted to study this phenomenon. Thirty students were interviewed. Several reasons were expected to cause the theory-practice gap in nursing education. The most common reasons included that the theory was about building a knowledge base while practice was about learning nursing skills. Half of the students agreed that the clinical instructor played a major role in either increasing or decreasing this gap and that they had a major effect on their personal experience. Most of the students agreed that the laboratory training helped a lot to decrease the gap.

\section{Acknowledgment}

The authors are grateful to the Applied Science Private University, Amman, Jordan, for the partial financial support granted to this research project

\section{Author Contributions}

Ahmad Saifan: Study design, manuscript writing and overall supervision.

Mohannad Eid AbuRuz: Data collection, analysis and manuscript writing.

Rami Masa'deh: Data collection, analysis and manuscript writing. 


\section{Ethics}

This article is original and contains unpublished material. The corresponding author confirms that all of the other authors have read and approved the manuscript and no ethical issues involved.

\section{References}

Brasell-Brian, R. and E. Vallance, 2002. Clinical practice/education exchange: Bridging the theorypractice gap. Nursing Praxis N Z, 18: 17-26. PMID: 12113141

Braun, V. and V. Clarke, 2006. Using thematic analysis in psychology. Qualitative Res. Psychol., 3: 77-101. DOI: 10.1191/1478088706qp063oa

Brown, J., M. Nolan, S. Davies, J. Nolan and J. Keady, 2008. Transforming students' views of gerontological nursing: Realising the potential of 'enriched' environments of learning and care: A multi-method longitudinal study. Int. J. Nurs. Stud., 45: 1214-1232. DOI: 10.1016/j.ijnurstu.2007.07.002

Bryman, A., 2012. Social Research Methods. 1st Edn., Oxford University Press, New York, ISBN-10: 0199588058, pp: 766.

Budden, L., 1994. Nursing faculty practice: Benefits Vs costs. J. Adv. Nurs., 19: 1241-1246. DOI: $10.1111 /$ j.1365-2648.1994.tb01210.x

Chan, D.S., 2004. Nursing students' perceptions of hospital learning environments-an Australian perspective. Int. J. Nurs. Educ. Scholarship.

DOI: $10.2202 / 1548-923 X .1002$

Chapple, M. and E.S. Aston, 2004. Practice learning teams: A partnership approach to supporting students' clinical learning. Nurse Educ. Pract., 4: 143-149. DOI: 10.1016/S1471-5953(03)00038-6

Clare, J., J. White, H. Edwards and A. van Loon, 2002. Curriculum, clinical education, recruitment, transition and retention in nursing. AUTC Phase One Final Report, Flinders University, Adelaide, Australia.

Cohen, L., L. Manion and K. Morrison, 2000. Research Methods in Education. 1st Edn., Routledge Falmer, London.

Fairbrother, P. and S. Ford, 1998. Lecturer practitioners: A literature review. J. Adv. Nurs., 27: 274-279. DOI: $10.1046 / \mathrm{j} .1365-2648.1998 .00525 . \mathrm{x}$

Gallagher, P., 2003. Re-thinking the theory-practice relationship in nursing: An alternative perspective. Contemporary Nurse, 14: 205-210. DOI: $10.5172 /$ conu. 14.2.205

Hartigan, I., A. Cummins, E. O'Connell, M. Hughes and C.C. Hayes et al., 2009. An evaluation of lecturer practitioners in Ireland. Int. J. Nurs. Pract., 15: 280-286. DOI: 10.1111/j.1440-172X.2009.01763.X
Hewison, A. and S. Wlldman, 1996. The theory-practice gap in nursing: A new dimension. J. Adv. Nurs., 24: 754-761. DOI: 10.1046/j.1365-2648.1996.25214.x

Hickey, G., 1996. The challenge of change in nurse education: Traditionally trained nurses' perceptions of Project 2000. Nurse Educ. Today, 16: 389-396. DOI: 10.1016/S0260-6917(96)80043-8

Hislop, S., B. Inglis, P. Cope, B. Stoddart and C. McIntosh, 1996. Situating theory in practice: Student views of theory-practice in Project 2000 nursing programmes. J. Adv. Nurs., 32: 171-177. DOI: $10.1111 / \mathrm{j} .1365-2648.1996 . t b 03149 . \mathrm{x}$

Jeffreys, M.R., 2007. Tracking students through program entry, progression, graduation and licensure: Assessing undergraduate nursing student retention and success. Nurse Educ. Today, 27: 406-419. DOI: 10.1016/j.nedt.2006.07.003

Jonsén, E., H.L. Melender and Y. Hilli, 2013. Finnish and Swedish nursing students' experiences of their first clinical practice placement-a qualitative study. Nurse Educ. Today, 33: 297-302.

DOI: $10.1016 /$ j.nedt.2012.06.012

Landers, M.G., 2000. The theory-practice gap in nursing: The role of the nurse teacher. J. Adv. Nurs., 32: 1550-1556. DOI: 10.1046/j.1365-2648.2000.01605.x

Nabolsi, M., A. Zumot, L. Wardam and F. Abu-Moghli, 2012. The experience of Jordanian nursing students in their clinical practice. Procedia, 46: 5849-5857. DOI: $10.1016 /$ j.sbspro.2012.06.527

McCaugherty, D., 1991. The theory-practice gap in nurse education: Its causes and possible solutions. Findings from an action research study. J. Adv. Nurs., 16: 1055-1061. DOI: $10.1111 / \mathrm{j} .1365-2648.1991 . t b 03366 . x$

McKenna, L.G. and S.J. Wellard, 2004. Discursive influences on clinical teaching in Australian undergraduate nursing programs. Nurse Educ. Today, 24: 229-235. DOI: 10.1016/j.nedt.2003.12.009

Nahas, V.L., V. Nour and M. Al-Nobani, 1999. Jordanian undergraduate nursing students' perceptions of effective clinical teachers. Nurse Educ. Today, 19: 639-648. DOI: 10.1054/nedt.1999.0376

Newton, J.M., S. Billett, B. Jolly and B.A. Ockerby, 2009. Lost in translation: Barriers to learning in health professional clinical education. Learn. Health Soc. Care, 8: 315-327. DOI: $10.1111 /$ j.1473-6861.2009.00229.x

Nolan, C.A., 1998. Learning on clinical placement: The experience of six Australian student nurses. Nurse Educ. Today, 18: 622-629. DOI: $10.1016 / \mathrm{S} 0260-6917(98) 80059-2$ 
Parker, T.J. and C. Carlisle, 1996. Project 2000 students' perceptions of their training. J. Adv. Nurs., 24: 771-778. DOI: 10.1046/j.1365-2648.1996.25416.x

Polit, D.F. and C.T. Beck, 2010. Essentials of Nursing Research: Appraising Evidence for Nursing Practice. 1st Edn., Lippincott Williams and Wilkins, Philadelphia, ISBN-10: 1609130049, pp: 610.

Ranse, K. and L. Grealish, 2007. Nursing students' perceptions of learning in the clinical setting of the dedicated education unit. J. Adv. Nurs., 58: 171-179. DOI: $10.1111 / \mathrm{j} .1365-2648.2007 .04220 . \mathrm{x}$

Steele, R.L., 1991. Attitudes about faculty practice, perceptions of role and role strain. J. Nurs. Educ., 30: 15-22. PMID: 1847405
Stockhausen, L.J., 2005. Learning to become a nurse: Students' reflections on their clinical experiences. Aus. J. Adv. Nurs., 22: 8-14. PMID: 16499235

Upton, D.J., 1999. How can we achieve evidencebased practice if we have a theory-practice gap in nursing today? J. Adv. Nurs., 29: 549-555. DOI: $10.1046 /$ j.1365-2648.1999.00922.x

White, R. and C. Ewan, 1997. Clinical Teaching in Nursing. 1st Edn., Nelson Thornes, Cheltenham, ISBN-10: 0748731695, pp: 213. 